\title{
The Design Research of Improving Safety Facility Based on User Experience: a Case Study of Fire Extinguisher Box
}

\author{
Yun Dong ${ }^{1, a}$, Tao Huang ${ }^{1, b}$ and Guona Liu $^{2, c}$ \\ ${ }^{1}$ School of Art and Communication, Southwest Jiaotong University, Chengdu 610000, China; \\ ${ }^{2}$ Department of Digital Art, Chengdu Neusoft University, Chengdu 610000, China. \\ adongyun9006@126.com, 'besignhuangtao@163.com, 'cliuguonaliuguona@163.com
}

Keywords: safety facility, fire extinguisher box, user need, user experience

\begin{abstract}
User experience of safety facility is very important, and good experience helps users save themselves better and faster from dangerous situation. To improve user experience of using safety facilities, potential user needs and their psychological states should be focused in design. In this research, fire extinguisher box of public transport system is as the case study to discuss the improvement of safety products. The research is separated in three parts: finding out potential user needs, analyzing the problems, and solving the problems on the aspects of operation, psychological association, form and color.
\end{abstract}

\section{Introduction}

Safety facility in public places is vital for lives of people when emergency happens. In the design of safety facility, designers are faced with many problems in using a safety facility, such as the instant use of the facility, the risk of using process, etc. According to Jiang's research, there are two principles about safety facility should be considered in designing: one is to focus on the potential safety risk which might exist in regular using; the other is to prevent the product from using wrongly ${ }^{[1]}$. So when designing all the safety facilities and products, we should follow the two principles. However, some user needs that should be noticed in the design process are usually neglected.

Sometimes in public places, there are some events and disasters happened unexpectedly, such as fire disaster on buses. For example, a fire disaster happened on bus in Guiyang in July 2010, and caused 6 people died and 35 people injured ${ }^{[2]}$. The function of fire suppression has usually been focused, but in using fire suppression, for an instance, the requirement of the easy and quick action of taking out fire extinguisher from the box is usually neglected. Therefore, in designing fire extinguisher, external and potential problems should be both investigated, in order to promote the user experience.

In this way, safety facility could play a better role when emergency of fire happens, and the "safety" would be promoted when people using the facilities.

\section{Problems of fire extinguisher box in the interior of public transport}

Traditional marketing research is based on focus groups and questionnaires, but not on deeper levels of experience: know, feel and rream $^{[3]}$. Only to find and understand the deeper level of user's expression, the real user needs could be understood by designer. To safety products installed in public places, the users are citizens who are not experts of product structure or have not been trained to face with emergency, so traditional investigation tools such as questionnaires cannot reflect the potential user needs. Actually, the users do not know what they really need in an unexpectedly dangerous situation. Designers cannot define a safety product according to respondents' opinion directly, but should explore their hidden needs through observation and thinking about their using process.

By analyzing the present fire extinguisher boxes in China and the interviews to the passengers who experienced emergency on bus, potential problems in using a fire extinguisher box could be revealed. 


\subsection{Analyzing the action of taking out extinguisher from the box}

In our daily life, many public places are equipped with fire extinguishers. According to the investigation of the present extinguisher boxes in China, a fact is revealed that when emergency happens, users have to take several actions to take out extinguisher from the box. As Figure 1 shows, users have to lift the extinguisher up, and turn the extinguisher to tilt it, and then they can take the extinguisher out of the box.

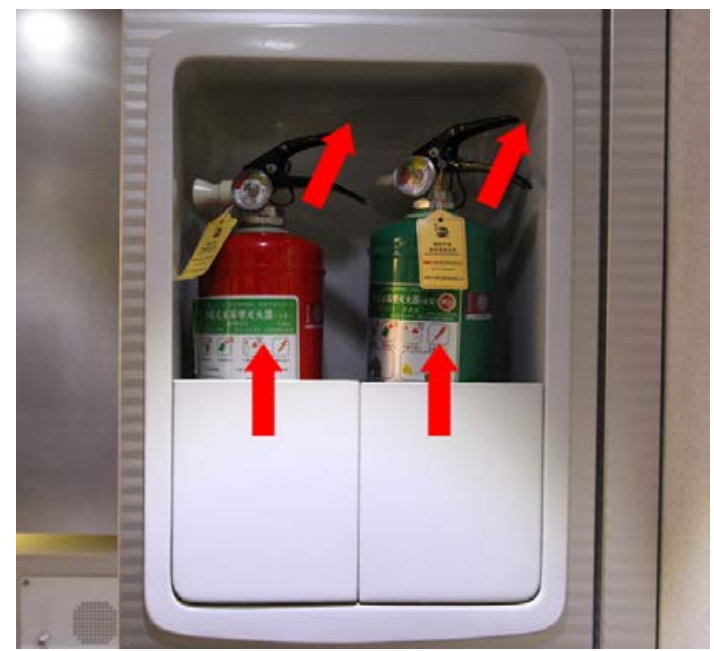

Fig. 1 The fire extinguishers and the box on high-speed train

Another situation is that users need to unlock or break some fixtures. As Figure 2, the extinguisher should be take out after unlocking the fixture, and as Figure 3, the glass on the surface should be break first.

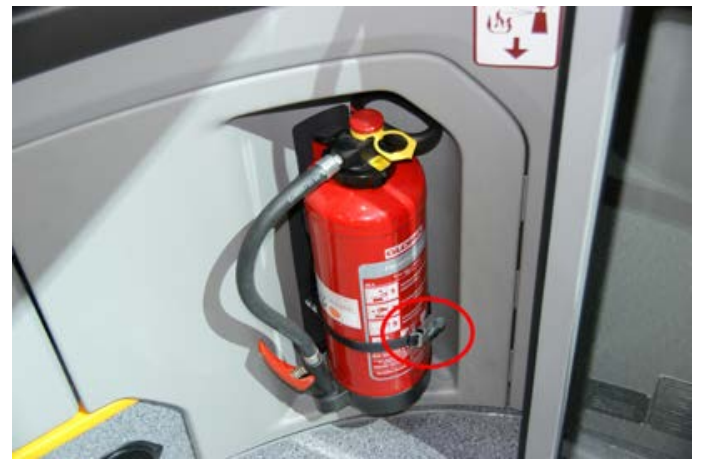

Fig. 2 Locked fixture

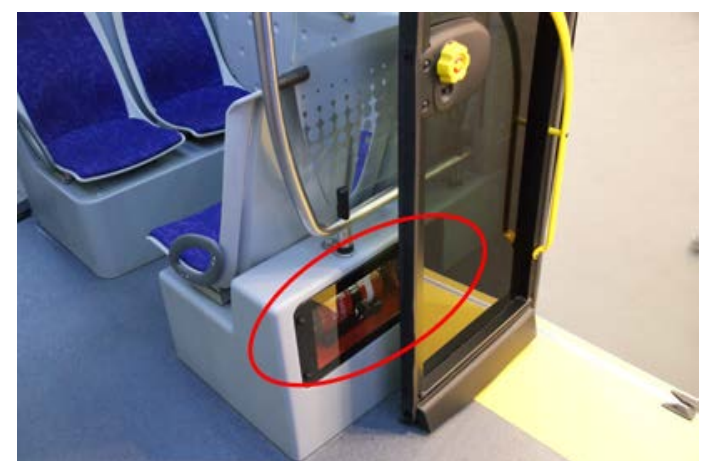

Fig. 3 The glass should be break first

According to the investigation of form of present extinguisher boxes, it is found that some of the boxes have sharp edges as Figure 4, so passengers might get injured by hitting the edges in a driving vehicle or high-speed train, especially to children.

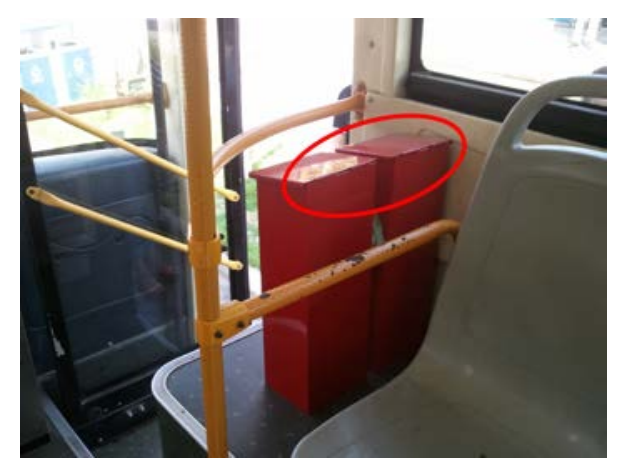

Fig. 4 Sharp edges 


\subsection{Analyzing users' intuitive emotion about extinguisher box}

In order to solve the problems of using extinguisher, interviews about fire accidents which happened on bus have been conducted. The interviewees were people who survived from fire accidents. They provide some important experiences when fire desaster happens on bus.

One interview of bus fire accident, which happened in Beijing in 2010 (Figure 5), is quoted in this section:

According to the driver, when he parked the No. 638 bus to the "South Huawei Bridge Station", a passenger suddenly noticed that some dense smoke came out from the rear of bus. The driver rapidly open the doors and shouted to the passengers: "Everyone get off the bus!"

Zhou was one of the passengers on bus, he confermed that after dense smoke came out, the driver was keeping guiding the passengers leave the bus. "The bus was full of smoke, it was very dangerous. Passengers left the bus with their hands covered on their nose and mouth." He said, after affirming that all the passengers have left the bus safely, the driver took out the extinguisher and walked to the rear of the bus, then begin to put out the fire. But it was a while since the fire started, it could not be quenched by extinguisher on bus. With the fire there waosive sound which sounds like "PING-PING". The driver had to leave the bus either and saw it bured. ${ }^{[4]}$

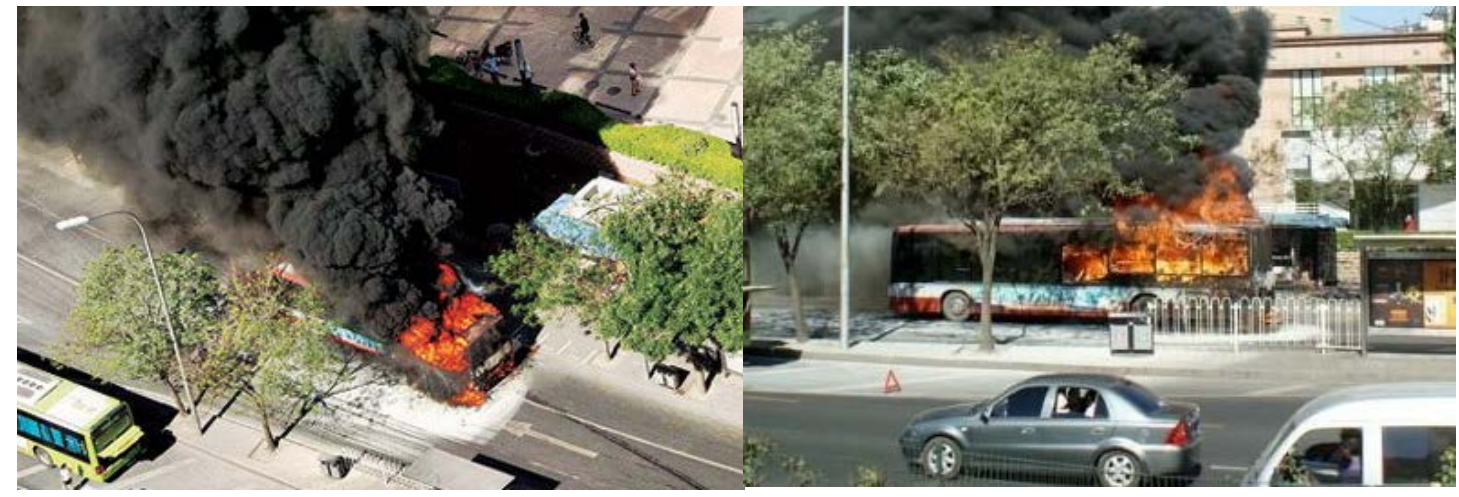

Fig. 5 Fire disaster on bus in Beijing

There is another interview of bus fire accident in Guiyang, which happened in April, 2014.

Shaoyin $\mathrm{Xu}$, one of the injured passengers who involed in a bus fire accident in Guiyang, has been interviewed by CCTV ( Figure 6). Main information is summarized as follow:

"I sitted on a single seat in the middle of the bus. The fire started at the rear, and quickly surrounded the back door. It was very crowed in the bus, and the front door was the only exit. Some passengers got injured due to crashing and squeezing when they were escaping. "[5]

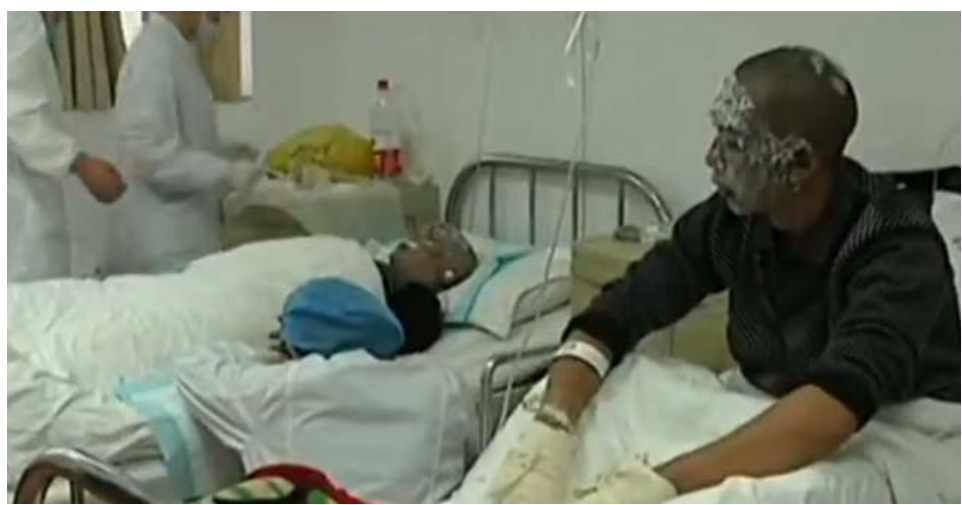

Fig. $6 \mathrm{Xu}$, one of the injured passengers, was being interviewed

According to the interviews, when the interviewees were facing with fire accidents in the interior of bus, there are two points of potential emotion they might have at that moment:

1. The situation was urgent, the extinguisher should be used to put out the fire quickly;

2. The extinguisher was hard to be taken out, and the work should be done by the driver or someone professional because passengers were not professional in using the extinguisher. 
Through the interviewees' experience, we can conclude that the intuitive ideas at the moment when emergency happened, what the users/passengers needed are as follows:

1. The extinguisher can be taken out at the moment when emergency happens;

2. Clear directions that can be easily understood immediately.

From the above interviews, the experience of the interviewees would help us to find out the problems in designing new fire extinguishers box.

\subsection{Summarize the user needs}

According to the analysis above, there are three main user needs of extinguisher box which in public transport systems:

1. Less actions. The extinguisher can be taken out from box at first time when emergency happens;

2. Clear guiding directions. Simple form would show users how to use the device. It would also reduce users' pressure from the extinguisher itself when facing with emergency.

3. A more familiar form is needed to reducing users' nervous feeling when fire emergency happens. It is very important to prevent users from getting hurt by misoperating the device without calmness.

The three users' needs are the fundamental elements in the design of fire extinguisher box, and also the ones of safety facilities.

\section{The user needs to contradictions}

The above user needs will bring contradictions in designing. Relatively, how to solve the contradictions will be based on the users' needs.

\subsection{Taking out extinguisher quickly from the fixture}

The need of taking out the extinguisher at the moment of fire emergency can be solved by shortening the time to taking out from the fixture. Also, less steps for the action is required if possible. The using environment of extinguisher boxes of public transport system, such as the ones in bus or high-speed train interior, is jolty and shaky, so the fixture is necessary. But unlocking the fixture means users have to spend more time to take out extinguisher. Hence, on the perspective of fixture design, the key to solve this contradiction is to explore the technique of taking out extinguisher and unlocking the fixture simultaneously. This contradiction is the priority to be solved due to the consideration of safety.

\subsection{Reducing users' pressure and the function of warning}

The function of warning is needed in extinguisher device. Users would be implied by psychological association that extinguisher should be used when emergency of fire happens, such as form, colors with cautions and some other design factors. High saturation colors would enhance physiological stimulation or arousal level, for instance, rapid heartbeat. ${ }^{[6]}$ Red with high saturation is more attractive, and usually designed as the color of warning and caution ${ }^{[7]}$, as well as the design of extinguisher box.

However, on the other side, users might get more psychological pressure while enhancing the warning function. Today's design of extinguisher box, such as the fixtures which hard to be unlocked and the color of high arousal level, makes users more nervous when facing with emergency. Users might want to avoid the extinguisher subconsciously and feel stressful to use it.

Nevertheless, when the pressure increases, it's hard for user to get attention. Usually simple unconscious action may also become difficult, and thinking under conscious is needed. ${ }^{[8]}$ So, solving this contradiction is helpful to improve self-saving action for passenger when emergency comes.

\subsection{Form and color}

In this paper, the using environment of extinguisher box is the interior of public transport system, so the environment is a space which is often crowded and narrow. Extinguisher should be used quickly when emergency happens, so it cannot be put in a secluded place, but an obvious place that can make it to be found easily and taken conveniently.

However, passengers might be thrown into a tizzy when facing with emergency, misoperation and sharp edges may lead the users getting hurt. Even in normal situation, with the shaking of driving bus 
or train, passengers might also get hurt due to collision with the extinguisher box, especially children. This contradiction needs to be solved through form design of products.

\section{Solve the contradictions}

The root of solving the problems is to solving the contradictions. To find out what problems should be solved in present products, then describe and define the contradictions of the problem accurately, then solve them through design methods.

In the case study of fire extinguisher in this paper, to solve the three contradictions above, user experience of extinguisher box and the users' self-saving ability in emergency of fire would be improved to a great extent.

\subsection{Improving the way of taking out the extinguisher and the fixture}

The target of improving the way of taking out the extinguisher from the fixture is to solve the contradiction between taking out extinguisher quickly and the stability of it. The improved inner structure of extinguisher box is shown as Figure 7:



Fig. 7 The structure of improved extinguisher box

There is a half-round clamp inside the box, and a raised circle on the bottom. When the bus or train is driving, the extinguisher will be stable because of these two parts.

When it comes to use the extinguisher, users can pull the handle on the cover of the box. With this action, the extinguisher will be pushed by the baffle which will move toward the same side with the handle. In this way, users can use one action to get the extinguisher out as Figure 8. 

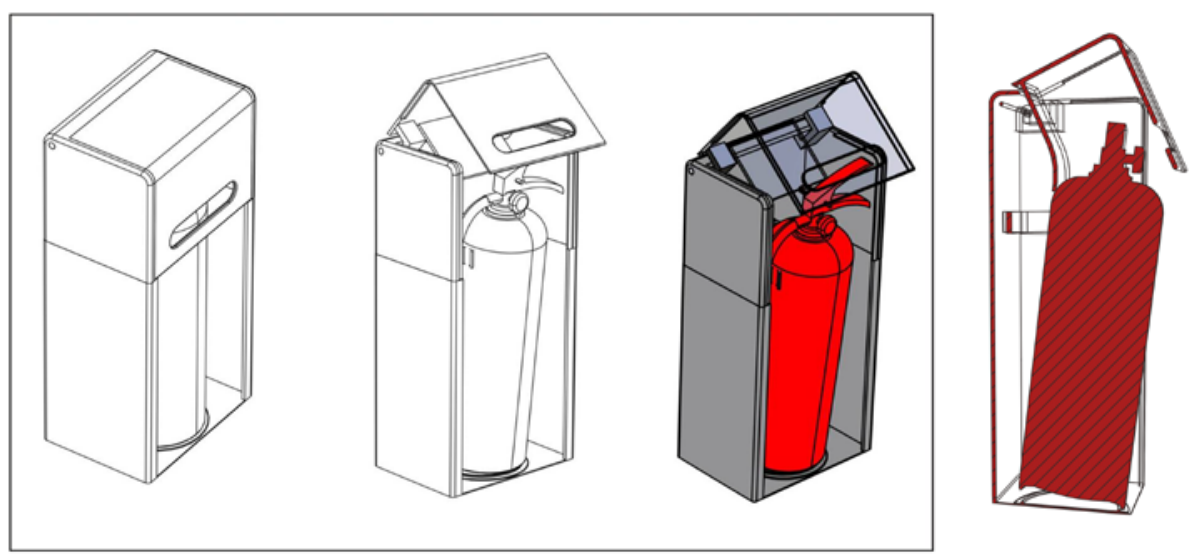

Fig. 8 The way of taking out the extinguisher

This way can solve the contradiction between taking out extinguisher quickly from the fixture of it and stability of the extinguisher. Extinguisher is put inside the box and fixed by the fixture. It is safe in driving and would not be bottom up to cause accident.

\subsection{The Use of Transparent Material and the Guide of Function}

In the improved design scheme, the top cover of the box is made of transparent toughened glass. This way makes user see the inside extinguisher directly and then have the intuitive cognition of the function-to extinguish fire when emergency comes.

Moreover, the transparent cover reduces the colored area of the whole box. High saturation red of warning function is still retained on the box surface, and less red can reduce the uncomfortable and negative stimulation to passengers, as well as to reduce the users' potential psychological pressure.

On the semantics of form, the way of opening the box is pulling the cover towards front as Figure

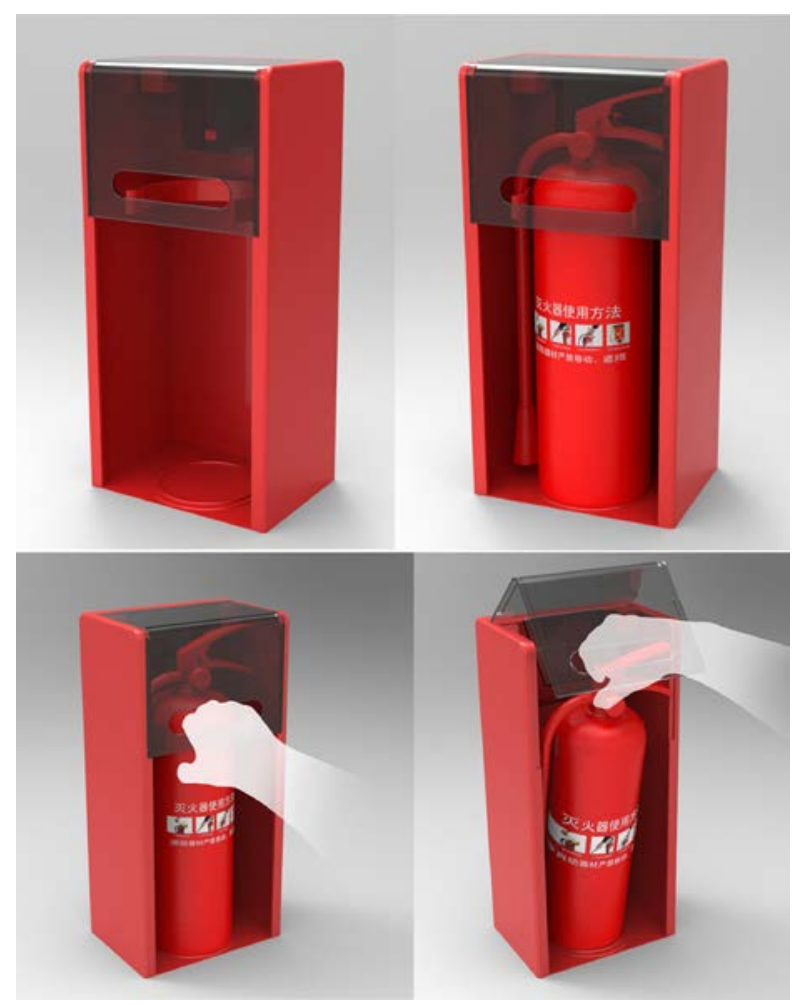

9.

Fig. 9 Clear functional guiding for users

The position of the handle is designed at the front side of the box to tell users the way of opening the box directly and clearly. In this way, the operation of the box was clear, and misoperation which 
caused by design could be avoided. Intuitive operation also reduces users' rejection and fear of profession of safety products.

In this design, the semantics of form can cause the psychological association of easy to operate, and the form makes users feel less pressure about operating the extinguisher.

\subsection{More Friendly and Harmless Form}

Fillets and rounded edges are taken in the form design in this research to prevent passengers from getting injured when reaching and grasping the box. Otherwise, straight line is still the main factor in the whole style of the box. The overall box is designed as rectangular form to match the environment such as interior of bus, and also consistent with the speedy and strict style of public transport system.

The form of straight line has a higher arousal level, and brings tension and sharp feeling to the user, to make them have psychological association of rage and exciting. ${ }^{[9]}$ To combine straight and rounded factors in the design makes the product more friendly due to the smooth curve of the edges, and reduces users' pressure. The final design project is as Figure 10 shows.

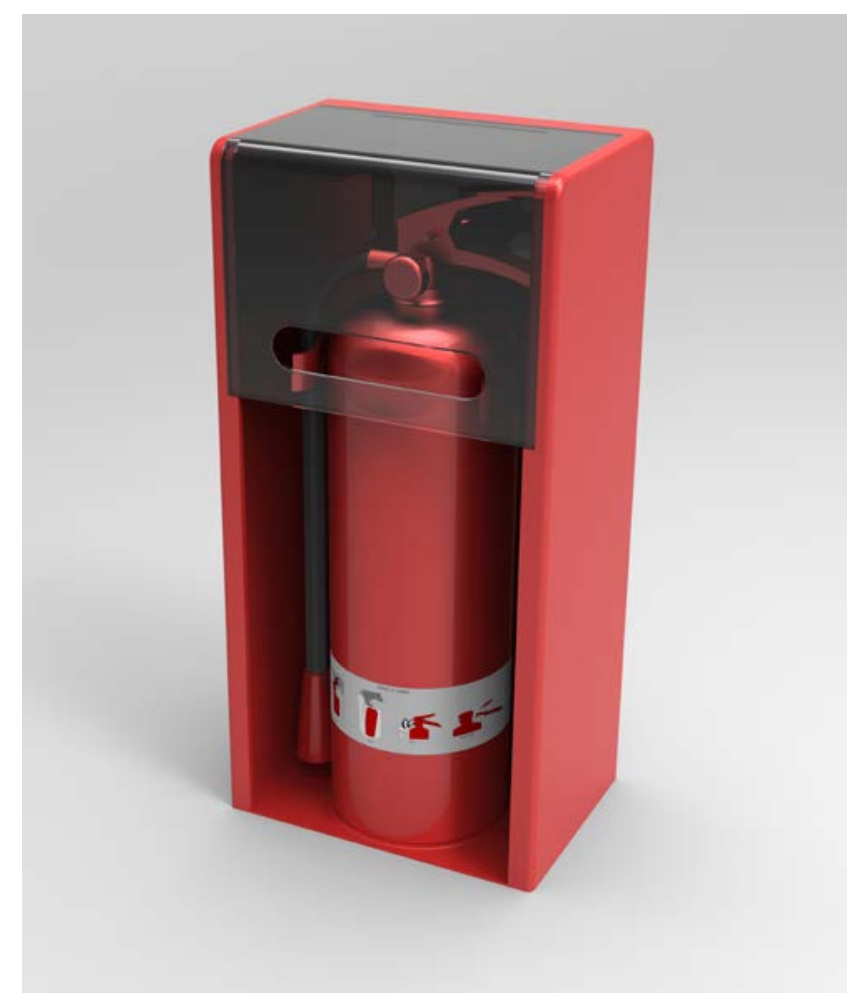

Fig. 10 The final project

\section{Summary}

User needs of safety facilities usually cannot be subjectively put forward by users themselves. The using process of safety facility should be observed and studied in design. Designers may explore the deep and potential user needs of safety products by analyzing the actions and mental activities in their using process. Among the analysis, the most important is to analyze the actions to make safety facility products easier and more convenient to use. Secondly, besides consideration of function, users' mental factors in using process may also be considered. Basis on the premise of warning function, psychological tension and pressure of users should be reduced as less as possible, as well as the sense of distance between user and the product. What's more, the harmony between safety products and the using environment may also be considered.

In the design of safety facility products, only the factors such as function, user need, mental activity and using environment are all involved in, physical and psychological user experience could be improved, and the idea of people-oriented design could be reflected in the design of safety facilities. 


\section{References}

[1] M. Jiang, H. Lin, Safety Perspectivism in Industrial Product Design, J. CSCD. Packaging Engineering. 31 (2010) 44-46

[2] Information on http://news.ifeng.com/society/special/guiyanggongjiao/

[3] I. Koskinen, T. Mattelmaki, K. Battarbee, Empathic Design: User Experience in Product Design, first ed., IT Press, Helsinki, 2003.

[4] Information on http://zt-rb.hangzhou.com.cn/system/2010/07/07/010776439.shtml

[5] Information on http://v.pps.tv/play_3CVRY7.html

[6] K. R. Fehrman, C. Fehrman, Color: The secret inluence, fist ed., Prentice Hall, New Jersey, 2000.

[7] T. Gorp, E. Adams, Design for Emotion (Yu J., Trans), first ed., Posts \& Telecome Press, Beijing, 2011.

[8] D.A. Norman, Emotional Design-Why We Love (or Hate) Everyday Things, fist ed., Basic Books, New York, 2004.

[9] H. Lundholm, The Affective Tone of Lines: Experimental Researches, J. Psychological Review. 28(1921), 43-60. 